\title{
O BRINCAR NA EDUCAÇÃO INFANTIL: ASPECTOS DE UMA EDUCAÇÃO DO CORPO E DE GÊNERO
}

\author{
Rosana Mancini Vieira \\ Universidade Estadual de Campinas, Campinas, São Paulo, Brasil \\ Helena Altmann \\ Universidade Estadual de Campinas, Campinas, São Paulo, Brasil
}

\begin{abstract}
Resumo
O presente artigo busca investigar como o brincar vem sendo compreendido pela produção de conhecimento da Educação Infantil, destacando como ela concebe sua importância e o que demonstra a respeito das práticas cotidianas. Procuramos também evidenciar como a educação do corpo e as relações de gênero permeiam estas questões, constituindo as experiências que as crianças vivenciam. Para isso, realizamos a análise da produção científica divulgada em oito periódicos nacionais entre 1996 e 2014. A análise nos revela um movimento em defesa da valorização do brincar que muitas vezes não tem seu espaço e tempo priorizados na rotina escolar, bem como a presença de uma educação do corpo que incide de forma diferente nos corpos de meninos e meninas e também nas experiências vividas por eles no brincar.
\end{abstract}

Palavras-chave: Educação Infantil; Brincar; Educação do corpo; Relações de gênero.

\section{Introdução}

Neste artigo buscamos investigar como o brincar vem sendo compreendido pela produção de conhecimento da Educação Infantil, como ela concebe sua importância e o que demonstra a respeito das práticas cotidianas. Procuramos também evidenciar como a educação do corpo e as relações de gênero permeiam essas questões, constituindo as experiências que as crianças vivenciam nesta primeira experiência educativa institucionalizada. ${ }^{1}$

A Educação Infantil é reconhecida como primeira etapa da educação básica pela Lei de Diretrizes e Bases da Educação 9394/96. Ela também determina a Educação Infantil como um direito da criança e dever do Estado. A configuração é uma conquista resultante da luta de diferentes segmentos sociais, dentre eles o movimento feminista e a comunidade acadêmica. Tal fato é também influência da consolidação da Educação Infantil como um campo de produção de conhecimento, sendo sistematizado e difundido por revistas científicas a partir da década de 1970.

Podemos destacar, também, o trabalho desenvolvido pela Fundação Carlos Chagas na sistematização e veiculação do conhecimento em educação. Essa se tornou pioneira na discussão sobre o ensino no país e as políticas voltadas para a educação de crianças de zero a seis anos. A criação da ANPEd (Associação Nacional de Pesquisa em Educação), em 1978, também pode ser mencionada como importante marco para as questões, pois, a partir de 1981,

\footnotetext{
${ }^{1} \mathrm{O}$ presente artigo apresenta parte dos resultados obtidos em minha pesquisa de mestrado, financiada pelo $\mathrm{CNPq}$, que trata da educação do corpo e de gênero na Educação Infantil tendo como base a produção de conhecimento da área de Educação, realizada na Faculdade de Educação Física da Unicamp.
} 
garantiu o funcionamento do Grupo Temático Educação de zero a seis anos (GT7) que se originou de discussões sobre as políticas sociais e educacionais daquela década.(ROCHA 1999; SILVA e PINHEIRO 2002; PINHEIRO e PINTO 2008).

Cabe enfatizar que o conhecimento de que trata a Educação Infantil, que tem como gênese a história da assistência à infância, possui como objeto a criança de zero a seis anos e a educação desta. O conhecimento produzido por esta etapa da educação busca tratar das necessidades colocadas pela prática educativa, que se revela multidisciplinar. A prática busca mediar situações as quais contemplem as diferentes áreas do desenvolvimento infantil, e também as diferentes formas de linguagem da criança pequena. Dentre estas formas de linguagem, o brincar destaca-se como uma das possibilidades que a criança tem para se expressar, a partir da exploração de brincadeiras, jogos e brinquedos que compõe as mediações da Educação Infantil.

É neste sentido que o brincar, nessa etapa da educação, é concebido como uma forma com a qual a criança elabora aspectos cognitivos, desenvolve habilidades corporais e, a partir das interações, vivencia a socialização. Diferentes aspectos podem ser evidenciados na brincadeira quando tratamos dela no ambiente educacional. Dentre esses podemos mencionar o caráter lúdico, que busca propiciar diversão e prazer. Outra dimensão a ser destacada tratase do caráter educativo, que preza a construção de conhecimentos. Cabe destacar que para que essas diferentes possibilidades aconteçam é necessário que o adulto, como mediador, propicie espaços e tempos adequados para que as brincadeiras ocorram livremente e de formas diversificadas.

Apresentada esta possibilidade de aliar o brincar ao trabalho pedagógico, não podemos deixar de conceber o brincar como uma expressão natural da criança. Tal consideração exige que compreendamos, como necessidade da criança, tempos e espaços para que possa brincar de forma espontânea, ampliando sua imaginação, seu contato com a natureza e sua relação com seu corpo e com o corpo do outro. Assim, cabe ao educador entender o brincar não apenas como recurso para motivar a abordagem de conteúdos, mas sim como uma forma de conhecer a criança e a partir disso mediar atividades de acordo com os interesses dela (INDAIÁ, 2013).

Apresentado pelo Referencial Curricular Nacional da Educação Infantil (RCNEI) como uma atividade significativa para o desenvolvimento da criança, o brincar possibilita a ela ressignificar sua realidade, proporcionando diferentes descobertas e promovendo autonomia e criatividade. Também é compreendido como um momento privilegiado de interação entre as próprias crianças da mesma idade, e de faixa etária aproximada, sendo importante na educação infantil garantir espaços para a realização dessa atividade. Segundo o documento, o "Brincar contribui, assim, para a interiorização de determinados modelos de adulto, no âmbito de grupos sociais diversos. Essas significações atribuídas ao brincar transformam-no em um espaço singular de constituição infantil.” (BRASIL, p. 27, 1998).

Também podemos destacar o artigo 227 da Constituição Federal de 1988, o artigo 31 da Convenção Internacional dos Direitos da Criança de 1989 e o Estatuto da Criança e do Adolescente (ECA) de 1990, como marcos legais que dão visibilidade ao brincar como um direito da criança. O ECA nos apresenta no artigo 16, parágrafo IV, o direito da criança à liberdade, que compreende "brincar, praticar esportes e divertir-se". Essas ações podem fazer parte do trabalho pedagógico desenvolvido no cotidiano escolar, de modo a garantir o direito das crianças de aprenderem diferentes brincadeiras e atividades que fazem parte do patrimônio cultural da humanidade.

Destacados o entendimento e a importância do brincar, compreendemos que a Educação Física pode contribuir para discussões e estruturação de práticas pedagógicas voltadas à Educação Infantil por também possuir como temáticas de pesquisa da área o brincar, o brinquedo, o jogo e a ludicidade. As temáticas relacionadas ao brincar, que também 
fazem parte do conhecimento de que trata a Educação Física, a cultura corporal (COLETIVO DE AUTORES, 1992), quando pensadas no contexto da pré-escola ou da creche passam a ter como objeto as ações ou o corpo da criança pequena. Portanto, acreditamos que a Educação Física pode auxiliar, a partir de um diálogo com a Educação, na construção de reinterpretações do corpo, do brincar e da cultura corporal da criança na Educação Infantil.

Entendemos que essas ressignificações sejam necessárias na Educação Infantil, pois, será neste contexto que a criança irá vivenciar situações que, de alguma forma, irão intervir na construção de sua identidade, nas relações de gênero e poderão inscrever marcas em seus corpos. A escola é um espaço normalizador que difunde códigos, condutas e padrões em suas práticas que, por vezes, acaba por disciplinar e restringir possibilidades (SOARES 2006, TABORDA DE OLIVEIRA 2006, DEBERTOLI 2008, MASCIOLI 2012) exercendo também uma educação que irá incidir de formas diferentes nos corpos, condutas e nas relações de meninos e meninas.

\section{Procedimentos metodológicos}

O estudo se caracteriza por ser qualitativo e utiliza como metodologia a pesquisa bibliográfica que se justifica diante da proposta do estudo de analisar a produção de conhecimento da Educação sobre Educação Infantil no tocante às temáticas da educação do corpo e de gênero. Para o desenvolvimento do trabalho, foi realizada uma busca pelo material proveniente da produção de conhecimento em Educação em periódicos nacionais de divulgação científica dessa área. Foram considerados como produção de conhecimento da área em questão: artigos, resumos e resenhas que tratassem das temáticas abordadas no estudo.

Como critérios considerados na escolha dos periódicos, definimos que deveriam apresentar classificação A1 no sistema Web Qualis $^{2}$; ser um periódico nacional voltado para a divulgação do conhecimento da área de Educação; bem como ter sua produção divulgada online com acesso por meio de busca de palavras ou indexação no próprio site ou em alguma base de dados como a Scopus e a Scielo.

O recorte temporal entre os anos de 1996 a 2014 tem como marco inicial o ano em que a Educação Infantil passa a ser reconhecida legalmente como a primeira etapa da educação básica pela legislação nacional. Outro fator relevante para a escolha por periódicos nacionais se deve ao fato destes tratarem de experiências e realidades condizentes com a educação de nosso país, divulgando a produção de um conhecimento que em grande parte é realizada em âmbito nacional.

De todos os 114 periódicos classificados como A1 em 2014 na área de avaliação em Educação no WebQualis, 35 eram brasileiros. Destes 35, apenas oito foram selecionados. Os demais periódicos nacionais não foram considerados como fonte para o estudo por não tratarem das temáticas que o mesmo se propõe a abordar, tratando de temáticas como história; ciências sociais e linguística. Após verificação no sistema da WebQualis foram selecionados os seguintes periódicos:

\footnotetext{
2 A consulta da avaliação dos periódicos classificados como A1, na área de educação, teve como referência a classificação atualizada no ano de 2014. Disponível em: $<$ http://qualis.capes.gov.br/webqualis/principal.seam $>$. Acesso em: nov. 2015.
} 
Quadro 1- Lista de periódicos selecionados para o estudo a partir do sistema Web Qualis.

\begin{tabular}{|ll|}
\hline ISSN & Título \\
$0100-1574$ & Cadernos de Pesquisa (Fundação Carlos Chagas) \\
$0102-4698$ & Educação em Revista (UFMG) \\
15179702 & Educação e Pesquisa (USP) \\
$0101-7330$ & Educação e Sociedade \\
$2175-6236$ & Educação e Realidade \\
$104-4060$ & Educar em Revista \\
$1980-6248$ & Pro- Posições (UNICAMP) \\
$1809-449 x$ & Revista Brasileira de Educação \\
\hline
\end{tabular}

Fonte: Qualis-Capes (2014 - 2015)

No total, foram consultados 3414 volumes. A busca pelo material a ser analisado utilizou palavras que, de alguma forma, contemplassem as temáticas do trabalho como Educação Infantil; creche; pequena infância; corpo; educação do corpo; movimento; Educação Física; brincar; jogos; gênero e relações de gênero e suas combinações. Foram considerados apenas os artigos que tratavam especificamente da Educação Infantil. Desse modo, a seleção dos artigos considerou aqueles que apresentavam em seus títulos, palavraschave e resumo às temáticas as quais o estudo se refere.

Dos 195 artigos encontrados sobre Educação Infantil, 42 contemplavam as temáticas do estudo por referirem-se à educação do corpo ou às relações de gênero nessa etapa da educação. Do montante, 19 foram selecionados para análise, pois se referiam ao brincar, ao movimento ou à Educação Física na Educação Infantil. A partir dessa, buscamos por informações que nos auxiliassem a atingir o objetivo principal do presente estudo, o de identificar as diferentes perspectivas que vem sendo concebidas sobre o brincar na Educação Infantil.

\section{O brincar a educação do corpo e de gênero na Educação Infantil: o que nos mostra a produção de conhecimento}

Voltando-nos para a análise dos artigos, procuraremos elucidar elementos que nos auxiliaram na compreensão de como o brincar e sua importância vem sendo apresentados por esta produção de conhecimento. De um modo geral, foi possível perceber que, em grande parte dos trabalhos a brincadeira é concebida pelos autores como uma maneira que a criança tem para compreender o meio no qual está inserida e expressar suas singularidades. Diante da perspectiva de que a brincadeira é uma forma de produção cultural e que essa se estabelece como ação social, a criança é apontada como um ator social, participando de forma ativa de sua cultura e sociedade, como apresentado no trabalho das autoras Prange e Bragagnolo (2012).

\footnotetext{
${ }^{3}$ Cabe destacar que parte das edições publicadas dentro do recorte temporal da pesquisa não se encontram disponíveis on-line, e para acessá-las foi preciso recorrer ao acervo da biblioteca da Faculdade de Educação da Unicamp. As revistas Educação e Realidade (UFRGS) e Educação em Revista (UFMG) não apresentavam indexação de suas edições a partir de 1996.
} 
Portanto, se reconhece que, por meio da brincadeira as crianças são capazes de se expressar de formas complexas, podendo tomar seus próprios corpos e objetos como instrumentos do brincar (RICHTER; GONÇALVES; VAZ, 2011). Neste contex to o corpo se destaca por oferecer meios para que se construa significados, vivencie ações, se expresse e experimente o mundo. Dessa forma, é no brincar que a criança vivencia as diferentes possibilidades que o seu corpo lhe proporciona, é também com o corpo que a criança pequena constrói significações.

Compreendendo a brincadeira com uma produção cultural que se estabelece como uma ação social (FERREIRA, 2004 apud PRANGE; BRAGAGNOLO, 2012), essa é apontada como espaço de compartilhamento no qual a socialização permite uma mediação de conhecimentos que proporciona apropriações (PRADO, 1999). Desse modo, outro fato associado à importância do brincar refere-se à possibilidade de construção de cultura pela própria criança, por meio da mediação com o outro uma vez que a criança se apropria de práticas, objetos, espaços de formas diversificadas e por meio das brincadeiras recria, reelabora e ressignifica conhecimentos (PRADO, 1999; FINCO, 2003; PRANGE; BRAGAGNOLO, 2012).

A influência das interações sociais para o desenvolvimento das singularidades da criança, que tem como instrumentos a brincadeira e os jogos, é outro fato que sustenta a importância do brincar (GRIGOROWITSCHS, 2010; PICCOLO, 2011; PRANGE; BRAGAGNOLO, 2012). Considerando os jogos relevantes para os processos de socialização infantil e formação do self da criança, como proposto por Grigorowitschs (2010), entende este conjunto de atitudes particulares e coletivas como constituintes de uma identidade individual. Piccolo defende que a criança "apesar de estar na sociedade desde que nasce, precisa se apropriar de um conjunto de elementos para se individualizar. Por isso, só existe individualidade a partir da coletividade, ninguém se humaniza isolado das relações sociais." (PICCOLO, 2011, p.215).

Apesar de todo este entendimento da importância e possibilidades do brincar apontadas pelos autores nos artigos analisados, questões são ressaltadas por eles no que se refere ao papel da escola em relação ao brincar. Essas questões vão desde o tempo e o espaço do brincar até a mediação dos professores para as interações entre os alunos na Educação Infantil. Ao nos depararmos com esse contexto, podemos perceber a presença de questões relacionadas à educação do corpo ocultas nas entrelinhas do cotidiano.

Alguns trabalhos demonstram conflitos e incompletudes ligados à questão do tempo e espaço do brincar na Educação Infantil. Mesmo diante do reconhecimento das características singulares da Educação Infantil e a percepção da importância da brincadeira como um elemento constitutivo do desenvolvimento infantil, encontramos contrastes no que se refere à maneira como os espaços escolares e as atividades são organizadas e mediadas. Podemos citar, por exemplo, a importância que vem sendo dada aos processos preparatórios para uma próxima etapa de ensino. A alfabetização é destacada em alguns dos trabalhos como ênfase do trabalho pedagógico (WAJSKOP, 1996; GALVÃO, 1996; KISHIMOTO, 2001; IZA; MELLO, 2009), o que faz com que espaços e tempos fornecidos ao brincar tornem-se escassos e não recebam devida atenção.

A Educação Infantil, muitas vezes, é considerada uma etapa transitória com ênfase em um trabalho em que se treinem habilidades para outras etapas da escolarização de modo a servir como preparação para atender requisitos de eficácia e produtividade da vida em sociedade, como destaca Wajskop (1996). Visando atingir esse propósito, o trabalho docente entra em conflito com o conhecimento trazido pela criança, bem como com suas necessidades, formas de brincar e expressar próprias das crianças.

A presença de uma normatização na Educação Infantil, que regula e modela as condutas infantis, acaba por fazer com que algumas especificidades da infância não sejam 
consideradas. A organização dos espaços e tempos, bem como os discursos e práticas instituídos por essa normatização, acabam por sufocar práticas nas quais a criança pode reinventar e ressignificar suas ações. Dentre elas, podemos destacar o brincar livre, criativo e espontâneo que é também um espaço de cultura e produção de conhecimentos da criança.

Cabe ressaltar que, quando tratamos da noção de educação do corpo, procuramos compreender as práticas, os espaços e formas de intervenção destinadas ao corpo que são incorporadas por diferentes práticas, dentre elas, as que se desenvolvem no contexto escolar. Para compreendermos essa noção, é preciso tornar visível os elos entre educação e corpo que ultrapassam a escola e tudo aquilo que nos parece naturalizado. Soares (2014) ressalta que, para que essa percepção seja possível, se faz necessário

[...] decodificar nossa singularidade corporal e analisar como ela vem sendo investida, desde a infância, ao longo de toda nossa vida, pelas marcas da cultura; do quanto somos tributários de processos que incidem sobre nossos corpos para modificar e revelar comportamentos e condutas as mais íntimas e ocultas, tanto quanto as mais visíveis e públicas. (SOARES, 2014, p.219)

Encontramos, nos trabalhos, exemplos que ilustram traços de uma normatização que incide sobre os espaços, ações e corpos das crianças. Dentre esses, apontamos a estética escolar que busca internalizar predisposições, como a disposição separadas das lancheiras de meninas e meninos (MEDEIROS, 2003; WAJSKOP, 1996), a manutenção de uma postura corporal para a realização de atividades e para o brincar (GALVÃO, 1996; WAJSKOP, 1996; IZA; MELLO, 2009) e a realização de atividades de repetição dirigidas (WAJSKOP, 1996; IZA; MELLO, 2009). São ações como essas que irão refletir nas mais diferentes formas nas relações que as crianças estabelecem umas com as outras, com o brincar e também com o seu corpo, pois, são também formas de se educar o corpo.

A inadequação da escola diante das necessidades e possibilidades da infância também é demonstrada nos trabalhos de Galvão (1996) e Iza e Mello (2009), os quais destacam a contenção motora quase como uma regra, pois, "sentadas e prestando atenção" ou "quietas e caladas" eram as exigências voltadas às crianças durante a realização de atividades. Entretanto, como apresentado nos trabalhos das autoras, a solicitação de uma postura e de um ritmo padrão não era atendida por todos e o movimentar-se era visto e tratado como uma transgressão, levando a uma constante repressão e controle por parte da professora.

Mesmo após quase duas décadas da aprovação da LDB e elaboração dos RCNEIs e constante desenvolvimento de pesquisas voltadas para a área de Educação Infantil, verifica-se a permanência de práticas que visam à antecipação da escolarização. Embora pesquisas venham apresentando diferentes aspectos relacionados à importância do brincar, destacando que é por esse meio que a criança aprende e se desenvolve, o que alguns trabalhos revelam é que, na prática, a valorização de tempos e espaços destinados ao brincar não vem ocorrendo (SILVA, 2013).

Com relação a essa afirmação podemos apontar os trabalhos das autoras Iza e Mello (2009) e Prange e Bragagnolo (2012). No primeiro trabalho, as autoras destacam que a recorrente dificuldade das professoras em relação às atividades de movimento acaba refletindo em suas ações até mesmo durante o brincar livre, de modo que a ação dessas seja voltada ao controle dos movimentos da criança.

Já as autoras Prange e Bragagnolo (2012) afirmam, baseadas no trabalho de Finco (2003, 2007), que as crianças vêm sendo instruídas a silenciar-se ao invés de movimentar-se. As autoras ainda ressaltam a recorrente desconsideração das heterogeneidades no contexto da Educação Infantil que "preza pela ordem e disciplina, atuando como um instrumento normatizador, vigiando e controlando as crianças, especialmente seus corpos". (PRANGE; BRAGAGNOLO, 2012, p. 253). 
A organização do espaço, que muitas vezes não considera as necessidades da criança, é apresentada em alguns trabalhos como motivo de conflitos entre as crianças e delas com as professoras. A questão também é apontada como um fator que influencia as relações entre meninos e meninas, segundo Wajskop (1996). Nesse trabalho, a autora relata que a forma como a professora organizava a sala e suas ações, desde a disposição diferenciada de lancheiras de meninos e meninas até a organização de filas para a locomoção, separando-os, reafirmava a diferenciação entre meninos e meninas, resultando na falta de integrações.

Cabe destacar que a análise que propomos realizar a respeito das relações de gênero na Educação Infantil tem como embasamento a perspectiva dos Estudos Feministas. Ao concebermos instituição escolar também como um espaço onde o gênero se constitui, entendemos que é nesse espaço que serão instaurados as mais diferentes intervenções relacionadas a saberes e condutas, estabelecendo diferenças ao determinar modelos, espaços. Nesse sentido, a escola é igualmente responsável por produzir e manter diferenças. Louro (1997, p. 87-88) apresenta que a escola

[...] não apenas transmite conhecimentos, nem mesmo apenas os produz, mas que ela também fabrica sujeitos, produz identidades étnicas, de gênero, de classe; se reconhecemos que essas identidades estão sendo produzidas através de relações de desigualdade; se admitimos que a escola está intrinsecamente comprometida com a manutenção de uma sociedade dividida e que faz isso cotidianamente, com nossa participação ou omissão; se acreditamos que a prática escolar é historicamente contingente e que é uma prática política, isto é, que se transforma e pode ser subvertida; e por fim, se não nos sentimos conformes com essas divisões sociais, então, certamente, encontramos justificativas não para observar, mas, especialmente, para tentar interferir na continuidade dessas desigualdades..

A respeito das relações de gênero e o brincar podemos perceber que alguns trabalhos também apontam a escola como um espaço onde imposições de estereótipos de gênero, e também sexuais e raciais se fazem presentes construindo e mantendo as diferenças (GOBBI, 1999; FINCO, 2003; KUDE, KNÜPPE; PLENTE, 2004; PRANGE; BRAGAGNOLO, 2012). Esses estereótipos são reforçados constantemente em diferentes vivências diárias da criança na escola. Nos trabalhos analisados podemos perceber que essas imposições passam a ser percebidas desde atitudes, gestos, escolhas até em suas brincadeiras.

Como destacado por Finco (2003, p. 99), a escola "participa sutilmente da construção da identidade de gênero e de forma desigual. Esta construção inicia-se desde as primeiras relações da criança no ambiente coletivo da educação infantil." Nos deparamos, portanto, com uma escola que não é imparcial quanto às relações de gênero, porém pretende aparentar neutralidade ao mesmo tempo em que busca manter um controle e silenciar as questões evitando sua abordagem.

A não aceitação do uso do lápis vermelho por um menino (GOBBI, 1999); a representação de mulheres realizando atividades domésticas nos desenhos infantis (GOBBI, 1999); a não aceitação da menina no jogo de futebol (PICCOLO, 2011); o fato de menino não poder usar rosa (PRANGE; BRAGAGNOLO, 2012); o fato de um menino não ser aceito na brincadeira de cozinha (KUDE; KNÜPE; PLENTZ, 2004); o fato de a menina ser a mãe e o menino ter que ser o pai na brincadeira de casinha (KUDE; KNÜPE;PLENTZ, 2004; PRANGE; BRAGAGNOLO, 2012) são exemplos de situações encontradas nos trabalhos de como as imposições já estão impregnadas nos comportamentos das crianças de modo a serem expressas nos momentos de brincadeira.

Entretanto cabe destacar também trabalhos que apresentam outra perspectiva em relação à forma como as crianças reinterpretam as normas e papéis de gênero impostos, os casos de transgressões. Exemplos como o caso do menino que, ao brincar de casinha, 
amamenta o filho (PRANGE; BRAGAGNOLO, 2012); a utilização espontânea de brinquedos considerados "certos e errados" para cada sexo (FINCO, 2003); a participação de meninos em brincadeiras consideradas femininas como cuidar da casa e cozinhar (FINCO, 2003) ilustram a ressignificação que as crianças fazem dos contextos dos quais fazem parte. Neste sentido, Prange e Bragagnolo destacam que "apesar de estarem imersas em seu contexto cultural e interiorizar algumas questões relacionadas a gênero, as crianças conferem seus próprios sentidos, caracterizando seus aspectos singulares." (PRANGE; BRAGAGNOLO, 2012, p. 263).

Os trabalhos também destacam a importância do papel das professoras nas diversas mediações na Educação Infantil, uma vez que são capazes de muito influenciar nas questões voltadas para as relações de gênero, assim como a educação do corpo. A atuação da professora aparece em grande parte dos trabalhos como fator de grande potencial para transformar e ressignificar as experiências e relações vivenciadas pelas crianças de forma que estas sejam não sexistas e livres de preconceitos (FINCO, 2003; KUDE; KNÜPE; PLENTZ, 2004; PICCOLO, 2011; PRANGE; BRAGAGNOLO, 2012).

Quanto à resistência em brincar com brinquedos de meninas apresentado por meninos, as autoras Kude, Knüppe e Plentz (2004) defendem que o comportamento é um reflexo da grande influência que os estereótipos e pressões sociais exercem sobre as escolhas das crianças, fazendo com que busquem reproduzir determinados padrões de comportamento. A construção de rótulos para os brinquedos como "apropriados" ou não para meninos e meninas criados por adultos, sejam familiares; professores ou a mídia, e em um primeiro momento sem significados para a criança, pode acarretar uma segregação durante o brincar. Esta segregação inviabiliza experiências e relações sociais importantes para a criança construir sua compreensão sobre as relações de gênero (FINCO, 2003).

Ao refletir sobre possíveis transformações das práticas docentes, Kishimoto (2001) defende que o espaço do brincar deve ser construído pela criança. Na mesma perspectiva, a variedade de brinquedos e a diversidade de brincadeiras, são apontadas por Finco (2003) como favoráveis para que o espaço do brincar seja desfrutado por meninas e meninos de forma igualitária. Ações como deixar disponível e permitir o acesso a diversos brinquedos para que as crianças experimentem e vivenciem diferentes papéis, a organização de brincadeiras e intervenções que não favoreçam o sexismo, são exemplos encontrados nos trabalhos como formas de criar experiências significativas para as crianças que podem surgir após uma reflexão sobre as práticas.

\section{Considerações finais}

A compreensão do brincar e da brincadeira como formas de participação da criança na construção do mundo, um conjunto de fenômenos humanos e culturais (DEBORTOLI, 2002), auxilia o entendimento do brincar como representante de uma possibilidade de construção da identidade. Essa construção torna-se possível porque as diferentes formas de expressão do brincar propiciam diálogos entre o sujeito consigo mesmo e com os outros, dessa forma, construindo relações. Portanto, o brincar pode ser pensado como um processo coletivo no qual é possível significar o mundo que nos cerca.

A análise dos trabalhos nos demonstra a percepção de que a criança, por meio do brincar, comunica-se e participa do mundo ao expressar sua compreensão e ressignificação sobre a realidade. E, assim, podemos evidenciar que a brincadeira é compreendida por esta produção de conhecimento como a maneira que a criança age no mundo, não apenas como uma preparação para esse, mas, como uma forma de comunicar-se, participar e estar nele. Nossa análise também constatou que a apropriação dos espaços pelas crianças é defendida na 
medida em que se acredita que essa possibilita à criança construir conhecimentos, um exercício de autonomia que se dá de forma dinâmica e diversificada.

Já a educação do corpo encontra-se nas entrelinhas do cotidiano e aparece nos trabalhos associada à contenção corporal, a conformação do espaço e ao preparo para próximas etapas do ensino. Essa ênfase dada ao autocontrole do corpo da criança em espaços e momentos destinados à aquisição de conteúdo acadêmico formal faz com que o brincar seja desvalorizado e o movimento passe a ser considerado uma transgressão, em alguns casos. Portanto, defendemos aqui que questões envoltas pela educação do corpo também devem ser questionadas, ressignificadas e até mesmo reconstruídas, uma vez que a Educação Infantil demanda um arranjo singular e flexível que pode reconhecer no movimento e no brincar, formas de experimentar e conduzir o aprendizado e a percepção de mundo pela criança.

Outro fato que pode ser evidenciado a partir de nossa análise trata-se da frequente abordagem de argumentos voltados para as relações de gênero, direta ou indiretamente. Percebe-se, portanto, um movimento que tenta trazer à tona e compreender esta temática como ferramenta para a desconstrução de imposições e oposições construídas historicamente. Mesmo que em alguns momentos a produção demonstre alguns paradigmas ainda presentes na prática cotidiana, a mesma busca também propor rupturas. Na medida em que apresenta novas perspectivas e alerta para os atuais desafios que a educação deve enfrentar, defende também que a criança e suas singularidades precisam ser tomadas como ponto de partida do trabalho pedagógico.

Dessa forma, podemos ressaltar a partir da análise do conhecimento científico difundido sobre brincar que as temáticas: educação do corpo e relações de gênero encontramse intricadas em diferentes dimensões da Educação Infantil, e a partir da relação que estabelecem entre si influenciam a forma como as crianças se constituem e estabelecem suas relações sociais. Fica evidente que a educação do corpo incide de forma diferente nos corpos de meninos e meninas inclusive nas experiências vividas por eles, até mesmo no brincar. A presença de estereótipos defendidos para cada gênero faz com que estas experiências sejam direcionadas para atingir expectativas construídas sobre o que é ser menino ou menina.

\title{
THE PLAY IN THE CHILDHOOD EDUCATION:ASPECTS OF AN EDUCATION OF BODY AND GENDER
}

\begin{abstract}
This article investigates how the play has been understood for the production of knowledge in the Childhood Education, highlighting how it conceives its importance and what it demonstrates about the daily practices. We also seek to emphasize how body education and gender relations permeate these issues, constituting the experiences children live. We analyze the production published in eight national journals between 1996 and 2014 . This analysis reveals a movement in defense of the appreciation of the play that often does not have its space or time as a priority in the school routine, as well as the presence of a body education which focuses differently in the bodies of boys and girls and also in their experiences in the play.
\end{abstract}

Keywords: Early Childhood Education; Play; Body Education; Gender Relations. 


\section{EL JUGAR EN LA EDUCACIÓN INFANTIL: ASPECTOS DE UNA EDUCACIÓN DEL CUERPO Y DE GÉNERO}

\section{Resumen}

Este artículo pretende investigar como el jugar se ha entendido por la producción de conocimiento de la Educación Infantil, destacando como ella concibe su importancia y lo que muestra a respeto de las prácticas cotidianas. También buscamos evidencias de cómo la educación del cuerpo y las relaciones de género subyacen estas cuestiones, constituyendo las experiencias que los niños viven. Para eso, se realizó el análisis de la producción científica divulgada en ocho revistas nacionales entre 1996 y 2014. Este análisis revela un movimiento en defensa de la valoración del jugar, que a menudo no tienen su espacio y tiempo priorizados en la rutina de la escuela, bien como la presencia de una educación del cuerpo que se centra de manera diferente en los cuerpos de los niños y las niñas y también en las experiencias vividas por ellos en el jugar.

Palabras clave: Educación Infantil; Jugar; Educación del Cuerpo; Relaciones de Género.

\section{Referências}

ALTMANN, H.; MARIANO, M.; UCHOGA, L. A. R. Corpo e movimento: produzindo diferenças de gênero na Educação Infantil. Pensar a Prática, [S.1.], v.15, n.2, abr. 2013.

BORBA, A. M. As Culturas da Infância nos Espaços-tempos do Brincar: estratégias de participação e construção da ordem social em um grupo de crianças de 4-6 anos. In: $29^{\circ}$ Reunião Anual da Anped, 2006, Caxambu. Anais 2006 da 29a Reunião Anual da anped: Educação, cultura e conhecimento na contemporaneidade, 2006. Disponível em:

<http://29reuniao.anped.org.br/trabalhos/trabalho/GT07-2229--Int.pdf>. Acesso em: 15 nov. 2015

BRASIL. Constituição da República Federativa do Brasil. Brasília, DF: Senado Federal, $1988,305$.

. Estatuto da Criança e do Adolescente. Lei nº 8.069, de 13 de junho de 1990.

Ministério da Educação e Cultura. Lei de Diretrizes e Bases da Educação Nacional. Lei $n^{\circ}$ 9394, de 20 de dezembro de 1996. Dispõe sobre as Diretrizes e Bases da Educação Nacional. Brasília, DF: MEC, 1996.

Ministério da Educação e do Desporto. Secretaria de Educação Fundamental. Referencial curricular nacional para a educação infantil. Brasília, DF: MEC/SEF, 1998.

BUSS-SIMÃO, M. Gênero como possibilidade ou limite da ação social: um olhar sobre a perspectiva de crianças pequenas em um contexto de educação infantil. Revista Brasileira de Educação (Impresso), v. 18, p. 939-960, 2013.

DEBORTOLI, J. A. O. ; As crianças e as brincadeiras. In: Alyson Carvalho; Fátima Salles; Marilia Guimarães. (Org.). Desenvolvimento e Aprendizagem. 1. ed. Belo Horizonte: Editora UFMG, 2002, v. 1, p. 77-88. 
. Reflexões sobre as crianças e a educação de seus corpos no espaçotempo de Educação Infantil. Paidéia (Belo Horizonte), v. 1, p. 79-111, 2008.

FERNANDES, R. S. Não brinco mais: a (des)construção do brincar no cotidiano educacional. Revista Pró-posições. Campinas, v.13, n.2 (38), p. 171-180.

FERREIRA, M. M. M. Do "avesso" do brincar ou... as relações entre pares, as rotinas da cultura infantil e a construção da(s) ordem(ens) social(ais) instituinte(s) das crianças no jardim-de-infância. In: CERISARA, A. B. ; SARMENTO, M. J. (Org.). Crianças e Miúdos: perspectivas sociopedagógicas da infância e educação. Portugal: ASA Editores, 2004. p. 55-104

FINCO, D. Relações de gênero nas brincadeiras de meninos e meninas na educação infantil. Pró-Posições, Campinas, v. 14, p. 89-101, 2003.

- A Educação dos Corpos Femininos e Masculinos na Educação Infantil. In: FARIA, Ana Lúcia Goulart de (Org.). O Coletivo Infantil em Creches e Pré-escolas: falares e saberes. São Paulo: Cortez, 2007. p. 94-119.

GALVÃO, I. A questão do movimento no cotidiano de uma pré-escola.. Cadernos de Pesquisa (Fundação Carlos Chagas), São Paulo, v. 98, p. 37-49, 1996.

GOBBI, M. A. Lápis vermelho e de mulherzinha? Relações de Gênero, desenho infantil e crianças pequenas. Revista Pró-posições, Campinas, v.10, p.169-193, 1999.

GRIGOROWITSCHS, T.; Jogo, mimese e infância: o papel do jogar infantil nos processos de construção do self. Revista Brasileira de Educação, v. 15, p. 230-246, 2010.

INDAIÁ, P. O brincar é parte essencial da Educação Infantil segundo especialistas. Rede Nacional Primeira Infância. 2013. Disponível em: <http://primeirainfancia.org.br/o-brincar-eparte-essencial-da-educacao-infantil-segundo-especialistas/> . Acesso em: nov. 2015.

IPA, Artigo 31 da Convenção dos Direitos da Criança: o desenvolvimento infantil e o direito de brincar. Associação Brasileira pelo direito de brincar, 2013. Disponível em:< http://brinquedoteca.net.br/wp-content/uploads/2013/04/DireitodaCrianca.pdf >. Acesso em: nov. 2015.

IZA, D. F. V.; Mello, M. A. Quietas e caladas: as atividades de movimento com as crianças na Educação Infantil. Educação em Revista (UFMG. Impresso), v. 25, p. 283/02-302, 2009.

KISHIMOTO, T. M.Froebel e a concepção de jogo infantil. Revista da Faculdade de Educação. Universidade de São Paulo, São Paulo, v. 1, n.1, p. 145-168, 1996.

- Brinquedo e brincadeira na educação japonesa: proposta curricular dos anos 90. Educação e Sociedade, Campinas, v. 60, p. 64-88, 1997.

KRAMER, S. A Fundação Carlos Chagas e a Educação Infantil no Brasil: uma trajetória de produção. Uma História Para Contar: A Pesquisa na Fundação Carlos Chagas, São Paulo: Annablume, v. 1, p. 13-58, 2004. 
KUDE, V. M. M. A construção do gênero e o brincar na educação infantil. Educação em Revista (UFMG), Minas Gerais, v. 40, 2004.

LOURO, G. L. Gênero, sexualidade e educação. Uma perspectiva pós-estruturalista. 03. ed. Petrópolis: Vozes, 1997. v. 01. 179p .

MASCIOLI, S. A. Z. Cotidiano escolar e infância: interfaces da educação infantil e do ensino fundamental nas vozes de seus protagonistas. 2012. 296 f. Tese (doutorado) Universidade Estadual Paulista, Faculdade de Ciências e Letras de Araraquara, 2012.

MEDEIROS, C. C. C. ; La escuela en el cuerpo: estudios sobre el orden escolar y la construcción social de los alumnos en escuelas. Educar em Revista. n. 21, p. 315-318. 2003.

PICCOLO, G. M.; Educação infantil: análise da manifestação social do preconceito na atividade principal de jogos. Educação \& Sociedade (Impresso), Campinas, v. 32, p. 205221, 2011.

PINHEIRO, M. C. M.; PINTO, G. U. . O conhecimento da Educação Infantil no Brasil: uma revisão da produção sobre as pesquisas na área. Travessias (UNIOESTE. Online), v. 2, p. 1$15,2008$.

PRADO, PD. ; As crianças pequenininhas produzem cultura? Considerações sobre educação e cultura infantil em creche. Pró-Posições (UNICAMP. Impresso), UNICAMP, v. 10, p. 110$118,1999$.

PRANGE, B.; BRAGAGNOLO, R. I. As singularidades das crianças pequenas expressas nas suas brincadeiras. Educação e Realidade, Campinas, v. 37, p. 251-272, 2012.

RICHTER, A. C. ; GONÇALVES, M. C. ; VAZ, A. F. Considerações sobre a presença do esporte na Educação Física Infantil: reflexões e experiências. Educar em Revista (Impresso), v. 41, p. 181-195, 2011.

ROCHA, E. C. A pesquisa em Educação Infantil no Brasil: trajetória recente e perspectiva de consolidação de uma Pedagogia da Educação Infantil. Florianópolis: Ed. UFSC, 1999.

SILVA, E. F; PIHEIRO, M, C. M. A Educação Infantil como campo de conhecimento e suas possíveis interfaces com a educação física. Pensar a Prática, [S.I], v.5,p. 39-57, nov.2006.

SILVA, J. R. A brincadeira na Educação Infantil (3 a 5 anos): uma experiência de pesquisa e intervenção. Educ. rev., Curitiba, n. 47, p. 340, mar. 2013 . Disponível em: <http://www.scielo.br/scielo.php?script=sci_arttext\&pid=S010440602013000100020\&lng=en $\&$ nrm=iso>. Acesso em: nov. 2015.

SOARES, C. L. (Coaut. de). Metodologia do ensino de educação física. São Paulo, SP: Cortez, 1992. 119p.

SOARES, C. L. Prefácio. In: TABORDA DE OLIVEIRA, M. A. (Org.). Educação do corpo na escola brasileira. 1. ed. Campinas: Autores Associados, 2006, v.1, p.X-XIX. 
Corpo, Conhecimento e Educação: notas esparsas. In: Carmen Lúcia Soares.

(Org.). Corpo e História. 3.ed. Campinas: Autores Associados, 2006, v. 1, p. 109-129.

. Verbete: Educação do corpo. In FENSTERSEIFER, P. E. ; GONZALEZ, F. J. (Org.) Dicionário Crítico de Educação Física. 3. ed. Ijuí: UNIJUI, 2014, p. 219-225.

Imagens da Educação no Corpo: estudo a partir da ginástica Francesa no séc. XIX. Campinas: Editora Autores Associados, 1998.

TABORDA DE OLIVEIRA, M. A.; Educação do corpo na escola brasileira: teoria e história. In: Marcus Aurelio Taborda de Oliveira. (Org.). Educação do corpo na escola brasileira. 1.ed. Campinas: Autores Associados, 2006, v. 1, p. 1-34.

TOZONI-REIS, M. F. C. A pesquisa e a produção de conhecimentos. In: PINHO, S.Z. (Org.). Cadernos de Formação: Formação de Professores. Educação, Cultura e Desenvolvimento, v. 3. São Paulo: Cultura Acadêmica, 2010, v. 3, p. 111-148.

VIANNA, C.; FINCO, D. Meninas e meninos na Educação Infantil: uma questão de gênero e poder. Cadernos Pagu (UNICAMP. Impresso), p. 265-284, 2009.

WAJSKOP, G. A brincadeira infantil na educação pré-escolar paulista e parisiense: o que pensam sobre elas os adultos? Pró-Posições (UNICAMP. Impresso), Campinas, v. 7, n.3, p. $1-10,1996$.

Recebido em: $11 / 12 / 2015$

Revisado em: 28/12/2015

Aprovado em: 19/01/2016

Endereço para correspondência:

rosanamancini@yahoo.com.br

Rosana Mancini Vieira

Universidade Estadual de Campinas, Faculdade de Educação Física

Departamento de Educação Física e Humanidades.

Avenida Érico Veríssimo, 701

Cidade Universitária

13083-851 - Campinas, SP - Brasil 